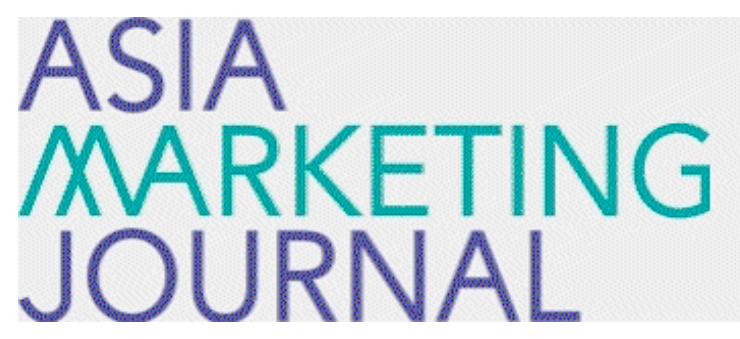

ASIA MARKETING JOURNAL

Volume 14 | Issue 1

Article 5

4-30-2012

\title{
신차와 줌고차간 프로모션의 상호작용에 대한 연구
}

Kwang Pil Chang

Follow this and additional works at: https://amj.kma.re.kr/journal

Part of the Marketing Commons

\section{Recommended Citation}

Chang, Kwang Pil (2012) "신차와 줌고차간 프로모션의 상호작용에 대한 연구," Asia Marketing Journal:

Vol. 14 : Iss. 1 , Article 5.

Available at: https://doi.org/10.53728/2765-6500.1473

This Article is brought to you for free and open access by Asia Marketing Journal. It has been accepted for inclusion in Asia Marketing Journal by an authorized editor of Asia Marketing Journal. 


\section{신차와 중고차간 프로모션의 상호작용에 대한 연구*}

\section{A Study on Interactions of Competitive Promotions Between the New and Used Cars}

장 광 필(Chang, Kwangpil)**

신차와 중고차가 함께 경쟁하는 시장에서 신차의 경쟁만을 모형화한다면 가격이나 기타 프로모션 탄력성의 추정이 왜곡될 수 있다. 그러나 자동차 시장을 연구대상으로 한 선행연구의 대부분이 신차 시장의 경쟁에만 관심을 기울였던 바, 합리적인 가격결정이나 프로모션 기획에 도움을 주기에 미흡한 점이 있었다. 본 연구는 신차의 가격결정 및 프로모션 기획이 향후 중고차 시장을 통해 리바운드되어 신차 매출에 다시 영향을 미친다는 점을 반영하여 모형을 설정하였다. 즉, 서로 다른 신차간의 (혹은 서로 다른 중고차간의) 교차탄력성보다. 동일 모델의 신차와 중고차간의 교차탄력성이 높다는 가정 하에 모형을 설정하였다. 방법론적으로는 네스티드 로짓(Nested Logit) 모형을 설정하여 소비자의 자 동차 선택은 단계적으로 이루어진다고 가정하였다. 즉, 1 단계에서 자동차 모델을 선택하고, 모델이 정 해지면 2 단계에서 신차와 중고차 중 선택하는 구조를 가정하였다

실증분석은 미국 전역에서 2009년 1월부터 2009년 6월까지 판매된 모든 컴팩트 카 모델 중에서 시 장점유율 상위 9 개 모델의 신차와 중고차를 대상으로 하였다. 실증분석을 통하여 비교 대상 모형보다 제안된 모형이 모형 적합도 측면에서 우월하고 예측타당성도 높다는 것을 보여주었다.

제안된 모형으로 부터 추정된 모수를 사용하여 몇 가지 시나리오를 상정하여 시뮬레이션을 실시한 결과, 신차(중고차)가 점유율을 높이고자 리베이트를 실시할 경우 중고차(신차)는 현재의 시장점유율 을 유지하기 위해 대응 가격할인을 실시하게 되는데 할인 폭은 반대의 경우에 비해 높다는(낮다는) 점을 확인하였다. 또한 시뮬레이션 결과가 시사하는 바는 신차와 중고차가 함께 경쟁하는 시장에서 IIA(Independence of Irrelevant Alternatives)모형을 적용할 경우 동일모델의 신차와 중고차간의 교 차 탄력성을 과소평가하게 되어 현상유지를 위한 가격할인을 실시할 경우 적정한 수준이하로 하게 된다는 것이다.

핵심개념: 신차와 중고차 경쟁, 네스티드 로짓, 교차탄력성

* 이 논문은 2010년도 서울시립대학교 교내학술연구비에 의하여 연구되었음

*** 서울시립대학교 경영대학 교수(kpchang@uos.ac.kr) 


\section{I. 서 론}

이 연구는 포장소비재 시장에서의 A. C. Nielsen 패널자료와 유사한 수준의 개별적 거래자료 (disaggregate transaction data)를 사용하여 동일 브랜드의 신차와 중고차간 가격정책 혹은 프로모 션의 상호작용을 반영한 자동차 선택모형을 제안 하여 합리적인 가격정책과 프로모션을 기획할 수 있는 방법론을 제시하는 것이다. 국내에서는 $\mathrm{A}$. C. Nielsen의 패널자료와 유사한 수준의 자동차 거래 자료가 수집되고 있지 않지만, 미국 내에서 는 그러한 자료가 수집되고 실제 마케팅전랴 수 립에 사용되고 있는 실정인 바, 국산 자동차의 미국시장 내에서의 경쟁력 강화를 위해서 가용한 자료를 적절하게 사용할 수 있는 방법론의 개발 과 모형이 필요하다고 판단된다. 특히 신차의 가 격정책이 중고차 가격과 매출에 미치는 영향과 그 반대의 영향을 반영한 모형을 통해 동일 브랜 드의 신차와 중고차의 점유율을 의도한 대로 관 리할 수 있는 방법론을 제시하고자 한다.

국내외를 통해 자동차 시장을 대상으로 한 다 수의 실증연구는 특정 세그먼트(e.g. mid-size sedan 또는 van)의 신차를 분석단위로 하였다. 예를 들면, 고려상표군이 신차에 한정되었으며. 세그먼트간의 경쟁, 시장구조분석, 신차간의 대 체가능성, 가격내생성의 반영, 물리적 속성과 시 장점유율과의 관계 등 매우 다양한 주제의 연구 가 진행되었지만 대부분 신차에 국한된 연구였 다(e.g., Morton, Silva-Risso and Zettelmeyer 2003, Dasgupta, Siddarth and Silva-Risso 2007,
장광필 2003, 2010). 반면에 중고차 시장을 연 구대상으로 한 경제학 분야 논문의 대다수는 신 차에 대한 정부의 규제가 중고차 가격에 미치 는 영향을 경제학적인 관점에서 분석한 것이었 다(Berkovec 1985). 마케팅 분야의 연구로서 신차와 중고차 시장을 함께 분석한 연구 중에 본 논문의 주제와 관련이 있는 논문으로 Purohit (1992)와 Sullivan(1990)을 언급할 수 있는데 데 이터상의 문제, 즉, 자동차의 실제 거래 가격 대 신에 NADA Used Car Guide에 기록된 평균 가 격을 기초로 연도별 감가상각률을 적용한 가격을 사용한 한계점 때문에 신차 출시가 중고차 가격 에 미치는 영향에 대하여 상반된 결과를 보여주 고 있다. 그러나 박찬수(1998)의 연구는 이러한 한계점을 인식하고 실제 거래 가격을 사용하여 신차 출시가 중고차 가격에 미치는 영향을 브랜 드 자산 강화 측면에서 분석한 점이 주목할 만하 다. 즉, 신 모델이 구 모델의 이름을 승계하는 경 우에는 브랜드 자산을 강화함으로써 중고차 가격 이 신 모델의 출시에 영향을 받지 않거나 오히려 높아지는 경우가 발생함을 실증적으로 보이고 있 다. 신차 메이커의 중고차 가격관리의 질적인 측 면에서 중요한 시사점을 제공하고 있다. 본 연구 는 박찬수(1998)의 연구와 마찬가지로 실제 거래 가격을 사용함으로써 선행연구의 한계점을 극복 하고자 한다. 동시에 박찬수(1998)의 연구와는 달리 계량적인 측면에서 신차와 중고차의 가격정 책이나 프로모션의 상호작용이 각 각의 시장점유 율에 미치는 영향을 분석하고자 한다. 예를 들면 신차의 판매나 리스(lease)를 촉진하기 위해 가 격할인이나 리베이트 혹은 $\mathrm{APR}^{1)}$ 인하 등을 실행

1) Annual Percentage Rate, 이자율로서 미국 내 자동차회사의 경우 자동차 구매 시 financing을 해주는 회사를 소유하고 이자율을 조정함으로써 APR을 촉진수단으로 사용하고 있다. 
할 경우 향후 중고차 시장에 공급이 증가함으 로써 중고차 가격인하로 이어지고 신차와 중고 차의 대체가능성을 가정한다면 결국 신차의 판 매 감소를 예상할 수 있다. 자동차 시장의 경우 판매 감소에 대한 대응으로서 생산량을 줄이는 것은 가능한 대안이 아니다. 왜냐하면 생산설비 와 같은 고정비용이 높기 때문이며 생산량을 줄이더라도 미국의 경우 노동조합에 가입된 근 로자에게는 $95 \%$ 까지 임금을 지불해야하기 때 문이다. 또한 신차개발을 통한 신규수요 창출 역시 평균 5 년이 걸리기 때문에 당면한 수요 감소에 대한 적절한 대응은 될 수가 없다. 따라 서 중고차의 공급충격을 흡수하고 신차 수요 감소에 대응하여 현상을 유지하며 수익을 내는 것이 마케팅관리상 매우 중요한 이슈이며 그 대응수단으로서 가격이 다른 어떤 수단(i.e., 신 차개발 및 감산)보다 자동차 시장에서는 효과 적인 수단이 될 수밖에 없는 것이다.

신 모델과 구 모델이 함께 경쟁하는 대표적인 내구재 시장에서 동일 브랜드의 신차와 중고차 간의 경쟁을 구체적으로 모형화하지 않고 신차 간의 경쟁만을 모형화 할 경우 최적의 가격 및 프로모션 정책을 수립하는데 한계가 있을 것이 다. 이러한 국내외 연구동향을 고려할 때 신차 와 중고차 시장간 상호작용에 대한 연구는 자 동차 시장의 실증연구로서 매우 시의적절하며 필요할 것으로 판단된다. 이 연구에서는 신차와 중고차의 상호작용을 반영하는 모형을 제안하 여 추정된 모수를 바탕으로 신차의 가격인하 혹은 $\mathrm{APR}$ 인하, 리베이트가 중고차의 점유율에 미치는 영향과 그 반대의 영향을 이해하고자 한다. 또한 실제로 일어날 가능성이 높은 몇 가 지 시나리오에 대하여 시뮬레이션을 이용한 사
후분석을 통해 신차(중고차)의 프로모션에 대 응하여 중고차(신차) 점유율 유지를 위한 적절 한 대응 가격인하 수준을 찾는 방법론을 제시 하고자 한다.

\section{II. 연구모형}

소비자는 자동차 구입을 원할 때 신차뿐만 아 니라 중고차도 함께 고려한다는 가정 하에 모 형을 설정하였다. 모형 설정 시 구매의사 결정 에 대한 상이한 가정에 따라 세 가지 다른 모 형을 생각해 볼 수 있다. 먼저, 이 연구에서 제 안하는 모형으로서, 소비자의 자동차 선택은 단 계적으로 이루어진다고 가정하고 1단계에서 자 동차 모델을 선택하고, 모델이 정해지면 2단계 에서 신차와 중고차중 선택하는 구조를 가정할 수 있다(Brand-primary/New vs. Used-secondary 구조로서 $\mathrm{BNU}$ 모형이라 부른다). 제안된 모형 과 실증 비교할 수 있는 2 개의 경쟁 모형을 생 각해 볼 수 있다. 첫 째, IIA(Indepedence of Irrelevant Alternatives)모형으로서, 신차와 중 고차를 구분하지 않고 모두 대체가능한 대안으 로 간주하고 계층 없이 1단계에서 최종 선택을 한다는 가정이다(IIA모형). 둘 째, 2 단계 계층 구조를 가정하지만 제안된 모형과 의사결정 순 서에서 차이가 나는 모형으로서 1단계에서 신 차 혹은 중고차를 살지 결정하고, 2 단계에서 어떤 모델을 구입할지 결정하는 모형이다(New vs. Used-primary/Brand-secondary 구조로서, NUB 모형이라 부른다). 세 가지 모형의 적합도를 비 교함으로써 어떤 모형이 실제 구매의사 결정과 
정을 보다 잘 설명하는지 실증분석을 통하여 확 인하고자 한다.

\section{$2.1 \mathrm{BNU}$ 모형}

소비자 $c$ 가 $t$ 시점에 자동차 브랜드 $j$ 를 선택 한 조건 하에 신차 $n$ (중고차 $u$ )를 선택할 조 건부확률은 다음과 같이 정의한다.

$$
P_{t}^{c}(n \mid j)=\frac{\exp \left(U_{t j}^{c}\right)}{\exp \left(U_{t j n}^{c}\right)+\exp \left(U_{t j u}^{c}\right)}
$$

여기서 신차와 중고차에 대한 효용함수, $U_{t j n}^{c}$ 와 $U_{t j u}^{c}$ 는 각 각 다음과 같이 정의한다(오류항 생략).

$$
\begin{aligned}
U_{t j n}^{c} & =\alpha_{j n}+\beta_{1} L M O D E L_{t j}^{c}+\beta_{2} L_{M A K E_{t j}^{c}}^{c} \\
& +\beta_{3} P R I C E_{t j n}+\beta_{4} R E B A T E_{t j n}+\beta_{5} A P R F_{t j n} \\
& +\beta_{6} A P R L_{t j n}+\beta_{7} O D O M T R_{t j n} \\
U_{t j u}^{c} & =\alpha_{j u}+\beta_{1} L M O D E L_{t j}^{c}+\beta_{2} L M A K E_{t j}^{c} \\
& +\beta_{3} P R I C E_{t j u}+\beta_{4} R E B A T E_{t j u}+\beta_{5} A P R F_{t j u} \\
& +\beta_{6} A P R L_{t j u}+\beta_{7} O D O M T R_{t j u}
\end{aligned}
$$

효용함수에 포함된 변수의 정의는 다음과 같 다. 그 중에서 브랜드 선택모형 적용 시 주로 사 용된 충성도 변수(Siddarth, Bucklin and Morrison 1995, Bronnenberg and Vanhonacker 1996, Chiang, Chib, and Narasimhan 1999)와 마찬가 지 형태의 변수로서 자동차모델 선택에도 중요 한 영향을 미칠 것으로 예상되는 변수의 조작 적 정의는 다음과 같다.
$L M O D E L_{t j}^{c}$ : 소비자 $c$ 가 교환(trade-in)하는 모델과 모델 $j$ 가 동일할 경우 1 , 아니면 0 의 값을 갖는다. Lattin과 Bucklin(1989) 의 동적인(time-varying) 최근 상표충성 도(last brand loyalty)와 동일하다.

$L M A K E_{t j}^{c}$ : 소비자 $c$ 가 교환하는 모델의 메이커와 브랜드 $j$ 의 메이커가 동일한 경 우 중 그 모델과 모델 $j$ 가 다를 경우에만 1 , 아니면 0 의 값을 갖는다. ${ }^{2)}$

기타, 모형에 포함된 중요한 마케팅믹스 변수 는 다음과 같다.

$P R I C E_{t j n / j u} \quad$ : 옵션가격을 제한 모델 $j n$ 또 는 $j u$ 의 가격(vehicle price after market option)

$R_{E B A T E_{t j} / j u}$ : 모델 $j n$ 또는 $j u$ 의 리베이트 액수

$A P R F_{t j n / j u}$ : 모델 in 또는 $j u$ 구입비 대출 금의 연 이자율

$A P R L_{t j n / j u} \quad$ : 자동차 리스시 연 이자율 (중고차의 경우 0 )

$\mathrm{ODOMTR}_{t j \mathrm{j} / \mathrm{ju}}$ : odometer, 주행거리계에 나 타난 주행거리 (신차의 경우 0)

신차와 중고차 선택의 전 단계에서 브랜드 선 택 확률을 정의하면 다음과 같다.

$$
P_{t}^{c}(j)=\frac{\exp \left(V_{t j}^{c}\right)}{\sum_{k} \exp \left(V_{t k}^{c}\right)}
$$

2) 메이커가 동일한 경우 1 의 값을 갖게 되면, $L M O D E L_{j t}^{c}$ 과 상관관계 1 이 되므로, 모델은 다르지만 동일한 메이커일 경우 에만 1 의 값을 갖도록 조작한다. 
네스티드 로짓 (nested logit) 모형을 적용하여 브랜드 선택의 효용함수를 정의하면 브랜드 $j$ 의 신차와 중고차를 모두 포함하는 가치(inclusive value 혹은 category value)는 다음과 같이 정 의할 수 있다.

$$
V_{t j}^{c}=\rho \ln \left[\exp \left(U_{t j n}^{c}\right)+\exp \left(U_{t j u}^{c}\right)\right]
$$

여기서 $\rho$ 는 추정해야 할 모수로서 McFadden (1978)이 보여주었듯이 0과 1사이에 있어야 하며 그 범위를 벗어날 경우 모형 설정오류 (model mis-specification)에 해당된다. 특히 1 의 값을 가질 경우 네스티드 로짓모형은 단순 한 다항로짓 모형(multinomial logit model)으 로 축소되며 모든 브랜드의 신차와 중고차는 서로 대체가능한 대안으로 간주되며 특별한 의 사결정의 계층구조는 없는 것으로 본다. 본 논 문에서 제안된 BNU모형과 비교되는 NUB모형 은 다음과 같이 설정하였다.

\subsection{NUB모형}

소비자 $c$ 가 $t$ 시점에 신차(혹은 중고차 $u$ ) n 을 선택한 조건 하에 자동차 브랜드 $j$ 를 선택 할 조건부확률은 다음과 같이 정의한다.

$$
P_{t}^{c}(j \mid n)=\frac{\exp \left(U_{t j n}^{c}\right)}{\sum_{k} \exp \left(U_{t k n}^{c}\right)}
$$

브랜드 선택의 전단계인 신차의 선택확률은 다음과 같다.

$$
P_{t}^{c}(n)=\frac{\exp \left(V_{t n}^{c}\right)}{\exp \left(V_{t n}^{c}\right)+\exp \left(V_{t u}^{c}\right)}
$$

네스티드 로짓(nested logit) 모형을 적용하여 신차의 효용함수를 정의하면 신차의 모든 브랜 드를 포함하는 가치(inclusive value 혹은 category value)는 다음과 같이 정의할 수 있다.

$$
V_{t n}^{\mathrm{c}}=\rho \ln \left[\sum_{k} \exp \left(U_{t k n}^{c}\right)\right]
$$

$\mathrm{BNU}$ 모형과 마찬가지로 추정된 $\rho$ 의 값과 유 의성으로 모형설정의 적합성을 판단할 수 있다.

\subsection{IIA모형}

위에 언급된 두 가지모형과 비교되는 IIA모 형은 BNU모형이나 NUB모형의 $\rho$ 값을 1 로 고 정하여 추정한다. 즉, IIA 모형은 모든 브랜드 의 신차와 중고차는 서로 대체가능한 대안으로 서 계층적 의사결정 구조를 가정하지 않는다.

\section{III. 실증분석}

\section{1 자료}

이 연구에 사용된 자료는 미국 내 자동차업계 전문조사 연구기관인 J. D. Power \& Associates 사로부터 제공받은 것이다. 이 기관은 미국 전 역의 딜러로부터 자동차 거래정보(자동차가격, 리베이트액수, $\mathrm{APR}$, 고객의 인구통계학적 정 보, 리스/파이낸싱 같은 거래조건을 포함한 약 200 개의 변수)를 일별로 전송 받아 그 자료를 근 거로 자동차 메이커에 컨설팅서비스를 제공하 고 있다. 실증분석은 미국 전역에서 2009년 1월 
부터 2009년 6월까지 판매된 컴팩트 카(compact car) 시장을 대상으로 했다. 이 자료의 중요한 특성은 기존의 자동차 시장을 대상으로 한 연 구에서 사용한 총합자료와는 달리 개별적 거래 자료라는 것이다. 또한 A.C. Nielsen의 패널자 료와 마찬가지로, 자동차 모델선택에 영향을 미 칠 수 있는 변수의 cross-sectional/longitudinal variation을 모두 포함하고 있는 장점을 가지고 있다. 미국 전역에서 판매된 모든 컴팩트 카 모 델 중에서 시장점유율 상위 9 개 모델의 신차와 중고차를 실증분석에 포함했고, 자동차 메이커 별 모델명, 시장점유율과 차량 거래가격의 평 균치는 〈표 1〉에 제시된 바와 같다. 신차 거래
162,408 건과 중고차 거래 75,194 건이 분석에 포 함되었고 (총 237,602건), 거래자료를 무작위로 구분하여 모수 추정 (208,925건)과 예측타당성 (28,677건) 검증에 사용하였다.

\section{2 모수추정}

BNU모형의 경우 수식 (1)과 (3)의 곱으로 NUB모형의 경우 수식 (6)와 (7)의 곱으로 우 도를 구하고 최대화함으로써 모수를 추정하였 다. IIA모형은 BNU모형이나 NUB모형의 $\rho$ 값 을 1 로 고정하여 추정하였다.

〈표 1〉 모델별 시장점유율과 가격

\begin{tabular}{|c|c|c|c|c|}
\hline Nameplate & Model & new/used & M/S & Price \\
\hline Mazda & 3 & new & 0.062 & 16429 \\
\hline Honda & Civic & new & 0.174 & 16782 \\
\hline Chevrolet & Cobalt & new & 0.048 & 14929 \\
\hline Toyota & Corolla & new & 0.157 & 15985 \\
\hline Hyundai & Elantra & new & 0.039 & 15315 \\
\hline Ford & Focus & new & 0.048 & 14942 \\
\hline Volkswagen & Jetta & new & 0.092 & 20060 \\
\hline Nissan & Sentra & new & 0.042 & 15892 \\
\hline Kia & Spectra & new & 0.023 & 13942 \\
\hline Mazda & 3 & used & 0.023 & 13172 \\
\hline Honda & Civic & used & 0.051 & 14842 \\
\hline Chevrolet & Cobalt & used & 0.055 & 9639 \\
\hline Toyota & Corolla & used & 0.049 & 13319 \\
\hline Hyundai & Elantra & used & 0.017 & 11789 \\
\hline Ford & Focus & used & 0.040 & 11261 \\
\hline Volkswagen & Jetta & used & 0.038 & 16241 \\
\hline Nissan & Sentra & used & 0.026 & 12579 \\
\hline Kia & Spectra & used & 0.015 & 9824 \\
\hline
\end{tabular}

* 볼드체는 신차 


\section{IV. 모수추정 결과 및 사후분석}

\section{1 모수추정 결과}

네스티드 로짓모형과 IIA모형의 모형적합도 는 〈표 2〉와 같다. 네스티드 로짓모형 중에 $\mathrm{NUB}$ 모형은 $\rho$ 값이 1 보다 큰 값으로 추정되었 기 때문에 모형설정 오류에 해당된다. 즉 실증 에 사용된 데이터에서는 자동차 모델을 결정하 기 전에 신차와 중고차 구입의사를 먼저 결정 하는 의사결정 구조는 지지되지 않는 것으로 나타났다. 반면에 BNU모형은 IIA모형에 비해 우도비 검정(likelihood ratio test)을 통해 모 형적합도 측면에서 우월한 것으로 나타났으며 $\left(\chi^{2}=85>3.84, d f=1, \alpha=0.05\right)$, 이 점이 시사 하는 바는 신차간 혹은 중고차간의 대체율보다 같은 자동차모델의 신차와 중고차간 대체율이 높다는 것이다. 신차간의 경쟁, 혹은 중고차간 의 경쟁만을 연구한다면 IIA모형으로 묘사가 가능하지만, 신차와 중고차를 모두 포함한 경쟁 구도를 연구한다면 $\mathrm{BNU}$ 모형을 적용하는 것이 타당한 방법으로 판단된다. $\mathrm{BNU}$ 모형의 모수 추정치는 〈표 3 〉에 제시된 바와 같다. $\rho$ 값이 0.582 로서 모형의 적절성이 지지되었다. 기타 다 른 모수들도 예측한 부호를 갖는 것으로 나타
났다. 자동차 메이커와 모델에 대한 충성도는 높은 것으로 나타났다. 가격을 비롯하여, 자동 차 구입시 대출금 이자율, 리스시 이자율은 부 의 방향으로 유의하게 나타났으며 리베이트는 정의 방향으로 유의하게 나타났다. 마지막으로 주행거리가 많을수록 효용가치가 떨어지는 것 으로 나타났다. BNU모형에 따라 추정된 가격 탄력성 행렬은 〈표 4〉에 제시된 바와 같다. 같 은 자동차모델의 신차와 중고차간 교차탄력성 이 상대적으로 높게 나타났으며 이것은 $\rho$ 값이 모형설정 타당성의 근거가 될 수 있는 범위, 즉, 0 과 1 사이에 있기 때문이다.

\section{2 사후분석}

$\mathrm{BNU}$ 모형의 추정된 모수를 사용하여 몇 가지 시나리오를 상정하여 시뮬레이션을 실시하였다. 신차의 대표적인 프로모션 수단은 자동차 판매 시 리베이트와 리스 대출금 이자율할인이다. 반 면에 중고차의 경우는 가격과 구입시 대출금 이자율이다. 신차(중고차)의 주요변수를 변화시 킬 때 중고차(신차)는 현재의 시장점유율을 유 지하는 수준까지 주요변수를 변화시킬 것이라 는 가정 하에 가격할인 수준을 추정하였다. 추 정방식은 Lanczo의 iterative method를 수정하 여 다음과 같은 방식을 적용하였다.

〈표 2〉 모형 적합도

\begin{tabular}{|c|c|c|c|c|}
\hline 모형 & 모수의 갯수 & $\begin{array}{c}\text { Calibration log } \\
\text { likelihood }\end{array}$ & BIC & $\begin{array}{c}\text { Holdout } \log \\
\text { likelihood }\end{array}$ \\
\hline IIA 모형 & 24 & -531.601 .344 & -531.748 .341 & $-73,654.931$ \\
\hline NUB 모형 & 25 & $-531,599.236$ & $-531,752.358$ & $-73,647.282$ \\
\hline BNU 모형 & 25 & $-531,558.819$ & $-531,711.941$ & $-73,628.335$ \\
\hline
\end{tabular}


〈표 3〉BNU모형 모수 추정치

\begin{tabular}{|c|c|c|}
\hline 절편 $(\alpha)$ & 모수 추정치 & t-value \\
\hline Mazda 3 & 1.344 & 16.911 \\
\hline Civic & 3.451 & 43.132 \\
\hline Cobalt & 1.322 & 17.709 \\
\hline Corolla & 3.350 & 44.805 \\
\hline Elantra & 0.811 & 9.686 \\
\hline Focus & 1.927 & 26.184 \\
\hline Jetta & 2.196 & 22.449 \\
\hline Sentra & 1.450 & 17.611 \\
\hline Spectra & 0.409 & 6.790 \\
\hline Mazda 3 & 0.826 & 9.565 \\
\hline Civic & 2.646 & 31.760 \\
\hline Cobalt & 1.872 & 25.343 \\
\hline Corolla & 2.659 & 33.739 \\
\hline Elantra & 0.450 & 4.786 \\
\hline Focus & 2.055 & 27.474 \\
\hline Jetta & 1.781 & 17.207 \\
\hline Sentra & 1.248 & 14.432 \\
\hline Spectra (fixed parameter) & 0.000 & 0.000 \\
\hline
\end{tabular}

\begin{tabular}{|c|c|c|}
\hline 변수 & 모수추정치 & $t$-value \\
\hline$L M O D E L_{t j}^{c}$ & 4.124 & 47.781 \\
\hline$L M A K E_{t j}^{c}$ & 2.494 & 38.347 \\
\hline$P R I C E_{t j / j u}$ & -1.325 & -23.552 \\
\hline$R E B A T E_{t j / j u}$ & 2.124 & 12.325 \\
\hline$A P R F_{t j n / j u}$ & -0.158 & -22.920 \\
\hline$A P R L_{t j / j u}$ & -0.278 & -27.863 \\
\hline ODOMTR $_{t j n / j u}$ & -0.055 & -8.232 \\
\hline$\rho$ (dissimilarity coefficient) & 0.582 & 15.932 \\
\hline
\end{tabular}

* 볼드체는 신차

변수정의

$R=$ 신차가 제공하는 리베이트 (혹은 대출이 자율 할인을 환산한 리베이트)
$P=\left(P_{1}, \ldots, P_{n}\right)^{T}$, 중고차 모델 1 부터 $n$ 까지의 가격

$Q=\left(Q_{1}, \ldots, Q_{n}\right)^{T}, R$ 과 $P$ 에 상응하는 중고차 매출 
〈표 4-1〉 가격탄력성 행렬 (신차의 가격변화 대비)

\begin{tabular}{|c|c|c|r|r|r|r|r|r|r|}
\hline & Mazda 3 & Civic & Cobalt & Corolla & Elantra & Focus & Jetta & Sentra & Spectra \\
\hline Mazda 3 & -2.5056 & 0.4106 & 0.0836 & 0.3831 & 0.0767 & 0.1143 & 0.1488 & 0.0858 & 0.0443 \\
\hline Civic & 0.1375 & -2.1675 & 0.0780 & 0.3718 & 0.0728 & 0.1082 & 0.1419 & 0.0825 & 0.0421 \\
\hline Cobalt & 0.1351 & 0.3761 & -2.9355 & 0.3615 & 0.0914 & 0.1498 & 0.1459 & 0.0910 & 0.0618 \\
\hline Corolla & 0.1418 & 0.4112 & 0.0824 & -2.2370 & 0.0762 & 0.1142 & 0.1423 & 0.0883 & 0.0462 \\
\hline Elantra & 0.1416 & 0.4023 & 0.1033 & 0.3802 & -2.6667 & 0.1371 & 0.1488 & 0.0920 & 0.0542 \\
\hline Focus & 0.1373 & 0.3887 & 0.1110 & 0.3714 & 0.0895 & -2.9129 & 0.1468 & 0.0906 & 0.0586 \\
\hline Jetta & 0.1312 & 0.3745 & 0.0791 & 0.3392 & 0.0709 & 0.1073 & -2.8065 & 0.0759 & 0.0384 \\
\hline Sentra & 0.1479 & 0.4252 & 0.0962 & 0.4114 & 0.0860 & 0.1298 & 0.1489 & -3.0565 & 0.0549 \\
\hline Spectra & 0.1513 & 0.4287 & 0.1296 & 0.4267 & 0.1008 & 0.1665 & 0.1496 & 0.1091 & -2.9513 \\
\hline Mazda 3 & 1.3724 & 0.4236 & 0.0932 & 0.4018 & 0.0835 & 0.1268 & 0.1512 & 0.0932 & 0.0505 \\
\hline Civic & 0.1414 & 1.8558 & 0.0859 & 0.3866 & 0.0785 & 0.1188 & 0.1440 & 0.0886 & 0.0473 \\
\hline Cobalt & 0.1404 & 0.3901 & 0.9288 & 0.3847 & 0.0975 & 0.1621 & 0.1466 & 0.0986 & 0.0699 \\
\hline Corolla & 0.1455 & 0.4197 & 0.0926 & 1.8598 & 0.0832 & 0.1275 & 0.1444 & 0.0952 & 0.0528 \\
\hline Elantra & 0.1478 & 0.4209 & 0.1120 & 0.4076 & 1.2784 & 0.1489 & 0.1502 & 0.1002 & 0.0611 \\
\hline Focus & 0.1420 & 0.4024 & 0.1169 & 0.3923 & 0.0937 & 1.1601 & 0.1475 & 0.0964 & 0.0638 \\
\hline Jetta & 0.1355 & 0.3877 & 0.0863 & 0.3572 & 0.0759 & 0.1168 & 1.5013 & 0.0819 & 0.0428 \\
\hline Sentra & 0.1516 & 0.4357 & 0.1012 & 0.4275 & 0.0896 & 0.1365 & 0.1497 & 1.2656 & 0.0590 \\
\hline Spectra & 0.1520 & 0.4308 & 0.1294 & 0.4301 & 0.1009 & 0.1665 & 0.1496 & 0.1097 & 1.0993 \\
\hline
\end{tabular}

* 볼드체는 신차. 가로 모델의 가격변화율에 대한 세로 모델의 시장점유 변화율로 가격탄력성 계산

〈표 4-2〉 가격탄력성 행렬 (중고차의 가격변화 대비)

\begin{tabular}{|c|c|c|c|c|c|c|c|c|c|}
\hline & Mazda 3 & Civic & Cobalt & Corolla & Elantra & Focus & Jetta & Sentra & Spectra \\
\hline Mazda 3 & 0.5215 & 0.1255 & 0.0991 & 0.1251 & 0.0361 & 0.0993 & 0.0646 & 0.0552 & 0.0295 \\
\hline Civic & 0.0534 & 0.5572 & 0.0924 & 0.1207 & 0.0343 & 0.0942 & 0.0617 & 0.0531 & 0.0280 \\
\hline Cobalt & 0.0569 & 0.1233 & 1.0590 & 0.1295 & 0.0448 & 0.1328 & 0.0671 & 0.0603 & 0.0409 \\
\hline Corolla & 0.0560 & 0.1272 & 0.1001 & 0.5976 & 0.0368 & 0.1014 & 0.0630 & 0.0577 & 0.0308 \\
\hline Elantra & 0.0581 & 0.1291 & 0.1257 & 0.1322 & 0.5804 & 0.1206 & 0.0671 & 0.0603 & 0.0359 \\
\hline Focus & 0.0575 & 0.1269 & 0.1371 & 0.1319 & 0.0438 & 0.9761 & 0.0672 & 0.0599 & 0.0388 \\
\hline Jetta & 0.0502 & 0.1129 & 0.0906 & 0.1093 & 0.0322 & 0.0906 & 0.6359 & 0.0479 & 0.0254 \\
\hline Sentra & 0.0606 & 0.1359 & 0.1189 & 0.1412 & 0.0422 & 0.1161 & 0.0676 & 0.7993 & 0.0365 \\
\hline Spectra & 0.0651 & 0.1433 & 0.1671 & 0.1554 & 0.0513 & 0.1524 & 0.0703 & 0.0737 & 0.7312 \\
\hline Mazda 3 & -3.5382 & 0.1337 & 0.1128 & 0.1362 & 0.0401 & 0.1117 & 0.0676 & 0.0608 & 0.0335 \\
\hline Civic & 0.0567 & -3.6386 & 0.1036 & 0.1300 & 0.0377 & 0.1046 & 0.0643 & 0.0578 & 0.0314 \\
\hline Cobalt & 0.0604 & 0.1303 & -2.9066 & 0.1404 & 0.0490 & 0.1464 & 0.0689 & 0.0662 & 0.0463 \\
\hline Corolla & 0.0597 & 0.1345 & 0.1146 & -3.6779 & 0.0410 & 0.1144 & 0.0657 & 0.0629 & 0.0352 \\
\hline Elantra & 0.0620 & 0.1377 & 0.1398 & 0.1444 & -3.5467 & 0.1335 & 0.0693 & 0.0666 & 0.0406 \\
\hline Focus & 0.0603 & 0.1329 & 0.1471 & 0.1409 & 0.0468 & -3.1986 & 0.0686 & 0.0644 & 0.0423 \\
\hline Jetta & 0.0534 & 0.1200 & 0.1011 & 0.1184 & 0.0353 & 0.1002 & -3.8604 & 0.0524 & 0.0283 \\
\hline Sentra & 0.0629 & 0.1410 & 0.1268 & 0.1486 & 0.0446 & 0.1233 & 0.0689 & -3.6360 & 0.0393 \\
\hline Spectra & 0.0653 & 0.1439 & 0.1671 & 0.1563 & 0.0514 & 0.1527 & 0.0704 & 0.0741 & -3.3483 \\
\hline
\end{tabular}

* 볼드체는 신차. 가로 모델의 가격변화율에 대한 세로 모델의 시장점유 변화율로 가격탄력성 계산 
현재매출 유지조건

신차가 리베이트를 제공하지 않은 경우:

$$
R=0 \rightarrow P=P_{o}, Q=Q_{o}
$$

신차가 리베이트를 제공하는 경우 :

$$
R>0 \rightarrow P=P_{o}-d P, Q=Q_{o}
$$

즉, 신차가 리베이트를 제공하여도 가격할인 을 통해 중고차 매출은 현재매출 $Q_{0}$ 로 회귀한 다는 조건.

\section{추정목표}

Objective $=d P=$ ?

\section{수정된 Lanczos's iterative method}

iteration 1: $P^{(1)}=P_{o}$

$$
\begin{aligned}
& e^{(1)}=Q-Q_{o}, P^{(1)} \text { 에 상응하는 오차 벡터 } \\
& P^{(2)}=P^{(1)}+\lambda e^{(1)}, \lambda \text { 는 } 0 \text { 보다 큰 scaling factor }
\end{aligned}
$$

iteration n: $P^{(n)}$ 을 구해서 $\sum_{k=n_{o}}^{n} \alpha_{k} P^{(k)}$ 로 대체 한다. 여기서 $\alpha_{k}$ 는 다음 조건을 만족시킨다.

$$
\left\|\sum_{k=n_{o}}^{n} \alpha_{k} e^{k}\right\| \rightarrow{ }_{\alpha}^{\min } \text { subject to } \sum_{k=n_{o}}^{n} \alpha_{k}=1
$$

수학적으로 표현하면 위의 방식으로 나타낼 수 있고 직관적으로 예를 들어 설명하면, 중고 차의 대응이 없다는 가정 하에 신차가 1,000 불 리베이트를 실시하면 신차의 점유율은 올라가 고 중고차의 점유율은 떨어진다. 중고차는 원래 점유율을 회복할 때까지 가격인하를 실시하고 최초 리베이트를 실시하여 달성된 신차의 점유 율은 하향 조정되어 균형에 이르는 것이다.
Volkswagen사 Jetta의 신차와 중고차를 대상 으로 시뮬레이션을 실시하였다. 아래 제시된 시 나리오에 따른 시뮬레이션 결과는 다음과 같다.

- 시나리오 1: 신차 리베이트에 따른 중고차 가격인하

\begin{tabular}{|c|c|c|c|c|c|}
\hline \multicolumn{2}{|c|}{$\begin{array}{c}\text { 초기 신차 리베이트에 의한 } \\
\text { 점유율 변화 }\end{array}$} & \multicolumn{3}{|c|}{$\begin{array}{c}\text { 중고차의 점유율 유지를 위한 } \\
\text { 대응 가격인하 }\end{array}$} \\
\hline $\begin{array}{c}\text { 신차 } \\
\text { 리베이트 }\end{array}$ & $\begin{array}{c}\text { 신차 점유 } \\
\text { 율변화 }\end{array}$ & $\begin{array}{c}\text { 중고차 } \\
\text { 점유율변화 }\end{array}$ & $\begin{array}{c}\text { 중고차 } \\
\text { 가격인하 }\end{array}$ & $\begin{array}{c}\text { 조정된 } \\
\text { 신차 } \\
\text { 점유율변화 }\end{array}$ & $\begin{array}{c}\text { 조정된 } \\
\text { 중고차 } \\
\text { 점유율변화 }\end{array}$ \\
\hline$\$ 1,000$ & $15.81 \%$ & $-7.58 \%$ & $\$ 390$ & $14.53 \%$ & $0.00 \%$ \\
\hline$\$ 2,000$ & $33.89 \%$ & $-15.03 \%$ & $\$ 790$ & $31.27 \%$ & $0.00 \%$ \\
\hline$\$ 3,000$ & $54.56 \%$ & $-22.20 \%$ & $\$ 1,210$ & $50.24 \%$ & $0.00 \%$ \\
\hline
\end{tabular}

* 점유율변화는 현 점유율 대비 점유율 증가분 혹은 감소분의 퍼센트로 표기

- 시나리오 2: 신차 리스 대출이자율 인하에 따른 중고차 가격인하

\begin{tabular}{|c|c|c|c|c|c|}
\hline \multicolumn{2}{|c|}{$\begin{array}{c}\text { 초기 신차 대출이자 할인에 의한 } \\
\text { 점유율 변화 }\end{array}$} & \multicolumn{3}{|c|}{$\begin{array}{c}\text { 중고차의 점유율 유지를 위한 } \\
\text { 대응 가격인하 }\end{array}$} \\
\hline $\begin{array}{c}\text { 신차 } \\
\text { 대출이자을 }\end{array}$ & $\begin{array}{c}\text { 신찬 } \\
\text { 점유율변화 }\end{array}$ & $\begin{array}{c}\text { 중고차 } \\
\text { 점유율변화 }\end{array}$ & $\begin{array}{c}\text { 중고차 } \\
\text { 가젹인하 }\end{array}$ & $\begin{array}{c}\text { 조정된 } \\
\text { 신차 } \\
\text { 점유율변화 }\end{array}$ & $\begin{array}{c}\text { 조정된 } \\
\text { 중고차 } \\
\text { 점유율변화 }\end{array}$ \\
\hline $4.9 \%$ & $23.87 \%$ & $-10.97 \%$ & $\$ 570$ & $22.04 \%$ & $0.00 \%$ \\
\hline $3.9 \%$ & $36.64 \%$ & $-16.09 \%$ & $\$ 840$ & $33.92 \%$ & $0.00 \%$ \\
\hline $2.9 \%$ & $50.39 \%$ & $-21.09 \%$ & $\$ 1,120$ & $46.73 \%$ & $0.00 \%$ \\
\hline
\end{tabular}

- 시나리오 3: 중고차 가격인하에 따른 신차 가격인하

\begin{tabular}{|c|c|c|c|c|c|}
\hline \multicolumn{2}{|c|}{$\begin{array}{c}\text { 초기 중고차 가격할인에 의한 } \\
\text { 점유율 변화 }\end{array}$} & \multicolumn{3}{|c|}{$\begin{array}{c}\text { 신차의 점유율 유지를 위한 } \\
\text { 대응 가격인하 }\end{array}$} \\
\hline $\begin{array}{c}\text { 중고차 } \\
\text { 가격인하 }\end{array}$ & $\begin{array}{c}\text { 신차 } \\
\text { 점유율변화 }\end{array}$ & $\begin{array}{c}\text { 중고차 } \\
\text { 점유율변화 }\end{array}$ & $\begin{array}{c}\text { 신차 } \\
\text { 가격인하 }\end{array}$ & $\begin{array}{c}\text { 조정된 } \\
\begin{array}{c}\text { 신차 } \\
\text { 점유율변화 }\end{array}\end{array}$ & $\begin{array}{c}\text { 조정된 } \\
\text { 중고차 } \\
\text { 점유율변화 }\end{array}$ \\
\hline$\$ 1,000$ & $-3.34 \%$ & $21.77 \%$ & $\$ 230$ & $0.00 \%$ & $19.80 \%$ \\
\hline$\$ 1,500$ & $-5.16 \%$ & $34.20 \%$ & $\$ 350$ & $0.00 \%$ & $31.12 \%$ \\
\hline$\$ 2000$ & $-7.07 \%$ & $48.01 \%$ & $\$ 480$ & $0.00 \%$ & $43.42 \%$ \\
\hline
\end{tabular}


- 시나리오 4: 중고차 구입 대출이자율 인하 에 따른 신차 가격인하

\begin{tabular}{|c|c|c|c|c|c|}
\hline \multicolumn{2}{|c|}{$\begin{array}{c}\text { 초기 중고차 대출이자 인하에 의한 } \\
\text { 점유율 변화 }\end{array}$} & \multicolumn{3}{|c|}{$\begin{array}{c}\text { 신차의 점유율 유지를 위한 } \\
\text { 대응 가격인하 }\end{array}$} \\
\hline $\begin{array}{c}\text { 중고차 } \\
\text { 대출이자율 }\end{array}$ & $\begin{array}{c}\text { 신차 } \\
\text { 점유율변화 }\end{array}$ & $\begin{array}{c}\text { 중고차 } \\
\text { 점유율변화 }\end{array}$ & $\begin{array}{c}\text { 신차 } \\
\text { 가격인하 }\end{array}$ & $\begin{array}{c}\text { 조정된 } \\
\text { 신차 } \\
\text { 점유율변화 }\end{array}$ & $\begin{array}{c}\text { 조정된 } \\
\text { 중고차 } \\
\text { 점유율변화 }\end{array}$ \\
\hline $6 \%$ & $-2.30 \%$ & $14.39 \%$ & $\$ 160$ & $0.00 \%$ & $13.09 \%$ \\
\hline $5 \%$ & $-4.79 \%$ & $30.50 \%$ & $\$ 340$ & $0.00 \%$ & $21.51 \%$ \\
\hline $4 \%$ & $-7.48 \%$ & $48.47 \%$ & $\$ 500$ & $0.00 \%$ & $43.73 \%$ \\
\hline
\end{tabular}

리베이트 수준이나 대출이자율 인하 수준은 실제로 집행되는 수준을 포괄적으로 반영하도 록 하였으며 이에 대한 반응은 비교를 십게 하 기 위해 가격인하로 통일하였다. 제안된 모형 $\mathrm{BNU}$ 에 근거하여 4 개의 시나리오에 따라 실시 한 시뮬레이션 결과가 시사하는 바는 신차(중 고차)가 점유율을 높이고자 리베이트를 실시할 경우 중고차(신차)는 현재의 시장점유율을 유 지하기 위해 대응 가격할인을 실시하게 되는데 할인 폭은 반대의 경우에 비해 높다는(낮다는) 것이다. 프로모션의 비대칭적인 효과의 또 다른 예로 생각할 수 있을 것이다. 평균적인 교차탄 력성의 크기를 고려하면 BNU모형은 대응 가격 할인 폭을 IIA모형에 비해 높게 추정하고 있다. 반면에 신차와 중고차의 상호작용성을 간과하 고, 교차탄력성의 크기를 낮게 평가함으로써 IIA모형은 점유율 유지를 위해 집행해야 하는 가격할인을 최적수준 이하로 책정할 위험이 있 음을 알 수 있다.

다음으로 국산 자동차의 미국 내 시장경쟁력 을 제고하는 차원에서 가격정책의 시사점을 도 출하기 위해 추가적으로 현대 Elantra의 신차와 중고차 그리고 Elantra와 Toyota Corolla간의 리 베이트에 대응하기 위한 예상 가격인하를 시뮬
레이션하였다. 비교를 쉽게 하기 위해 리베이트 액수는 1,000 불로 통일하였다. 리베이트를 실시 한 모델의 점유율 변화와 리베이트에 대응하여 원래의 점유율 유지를 위한 가격인하는 다음과 같다.

\begin{tabular}{|c|c|c|c|}
\hline $\begin{array}{c}\text { 리배이트 } \\
\text { 실시모델 }\end{array}$ & $\begin{array}{c}\text { 리배이트 실시모넬의 } \\
\text { 점유율변화 }\end{array}$ & $\begin{array}{c}\text { Elantra 신차 } \\
\text { 대응 가격인하 }\end{array}$ & $\begin{array}{c}\text { Elantra 중고차 } \\
\text { 대응 가격인하 }\end{array}$ \\
\hline Elantra 신차 & $17.64 \%$ & --- & $\$ 375$ \\
\hline Elantra 중고차 & $23.84 \%$ & $\$ 235$ & -- \\
\hline Corolla 신차 & $14.17 \%$ & --- & $\$ 160$ \\
\hline Corolla 신차 & $14.10 \%$ & $\$ 206$ & -- \\
\hline
\end{tabular}

〈표 4〉의 교차탄력성 행렬에 비추어 예상할 수 있듯이 동일한 모델, 예를 들면 Elantra 신 차와 중고차간의 리베이트에 대응하기 위한 가 격인하 수준은 다른 모델, 즉, Corolla의 리베이 트에 대응하기 위한 가격인하 수준보다 높은 것으로 나타났다. 또한, Corolla의 리베이트에 대하여 점유율 유지를 위한 대응 가격인하 수 준은 Elantra 중고차가 신차보다 오히려 낮은 것으로 나타났다.

\section{V. 결론 및 향후 연구방향}

신차와 중고차가 함께 경쟁하는 시장에서 신 차의 경쟁만을 모형화한다면 가격이나 기타 프 로모션 탄력성의 추정이 왜곡될 수 있다. 그러 나 자동차 시장을 연구대상으로 한 선행연구의 대부분이 신차 시장의 경쟁에만 관심을 기울였 던 바, 합리적인 가격결정이나 프로모션 기획에 도움을 주기에 미흡한 점이 있었다. 본 연구는 
신차의 가격결정 및 프로모션 기획이 향후 중 고차 시장을 통해 리바운드되어 신차 매출에 다시 영향을 미친다는 점을 반영하여 모형을 설 정하였다. 즉, 서로 다른 신차간의 (혹은 서로 다른 중고차간의) 교차탄력성보다. 동일 모델의 신차와 중고차간의 교차탄력성이 높다는 가정 하에 모형을 설정하고 실증분석을 통하여 비교 대상 모형보다 제안된 모형이 모형 적합도 측 면에서 우월하고 예측타당성도 높다는 것을 보 여주었다.

실증분석에서 추정된 모수를 사용하여 몇 가 지 시나리오를 상정하여 시뮬레이션을 실시한 결과, 신차(중고차)가 점유율을 높이고자 리베 이트를 실시할 경우 중고차(신차)는 현재의 시 장점유율을 유지하기 위해 대응 가격할인을 실 시하게 되는데 할인 폭은 반대의 경우에 비해 높다는(낮다는) 점을 확인하였다. 시뮬레이션 결과가 시사하는 바는 신차와 중고차가 함께 경쟁하는 시장에서 IIA모형을 적용할 경우 동 일모델의 신차와 중고차간의 교차 탄력성을 과 소평가하게 되어 현상유지를 위한 가격할인을 실시할 경우 적정한 수준이하로 하게 된다는 것이다.

향후 연구방향에 대하여 논하자면, BNU모형 이 실증적 지지를 받은 것은 실제 소비자의 자 동차 구입 의사결정이 계층적이다는 측면도 있 지만, 자동차 매장이 주로 동일 모델의 신차와 중고차로 구성되어 있다는 측면도 있을 것이다. 즉, 특정 매장에 들어가서 자동차를 구입한다는 것은 이미 자동차 모델을 결정하고, 신차 아니 면 중고차를 구입하는 것이기 때문이다. 그러나 한 매장 내에 다양한 자동차 모델의 신차와 중 고차가 함께 진열되어 있다면 NUB모형이 가정
하는 바와 같이 신차나 중고차 구입을 먼저 결 정하고 모델을 선택하는 소비자 집단도 존재할 수 있다. 이러한 가능성은 향후 다른 데이터 소 스를 사용하여 실증분석을 한다면 확인 가능할 것으로 판단된다. 따라서 향후 연구모형은 $\mathrm{BNU}$ 모형과 NUB모형의 확률적 혼합모형 (probabilisitc mixture)을 고려할 수 있으며 홍미로운 연구주 제가 될 것으로 보인다.

〈논문 접수일: 2012. 02. 20〉 〈1차 수정일: 2012. 03. 17〉 〈게재 확정일: 2012. 03. 20〉

\section{참고문헌}

박찬수 (1998), “신차 출시로 인하여 중고차 가 격에 나타나는 대체효과와 브랜드자산 강화 효과에 관한 실증적 연구," 마케팅연구, 13 (2), 39-51.

장광필 (2003), “고려상표군을 반영한 자동차 시 장구조 분석모형," 마케팅연구, 18(2), 53-67. 장광필 (2010), "가격 내생성을 반영한 자동차 선택모형," 마케팅연구, 15(3), 51-69.

Berkovec, J. (1985), "New Car Sales and Used Car Stocks: A Model of the Automobile Market," Rand Journal of Economics, 16, 2(Summer), 195-214.

Bronnenberg, Bart J. and Wilfried R. Vanhonacker (1996), "Limited Choice Sets, Local Price Response, and Implied Measures of Price Competition," Journal of Marketing Research. 33(May), 163-173. 
Chiang, Jeongwen, Siddartha Chib and Chakravarthi Narasimhan (1999), "Markov Chain Monte Carlo Models of Consideration Set and $\mathrm{Pa}^{-}$ rameter Heterogeneity," Journal of Econometrics, 89(1-2), 223-248.

Dasgupta, Srabana, S. Siddarth and Jorge SilvaRisso (2007), "Lease or Buy: A Structural Model of the Vehicle Acquisition Decision," Journal of Marketing Research, 44(August), 490-502.

Kannan, P. K. and Gordon P. Wright, (1991), "Modeling and Testing Structured Markets: A Nested Logit Approach," Marketing Science, 10(Winter), 58-82.

Lattin, James M. and Randolph E. Bucklin (1989), "Reference Effects of Price and Promotion on Brand Choice Behavior," Journal of Marketing Research, 26 (August), 299310.

McFadden, Daniel (1978), "Modelling the Choice of Residential Location," Spatial Interaction
Theory and Residential Location. Amsterdam: North-Holland.

Morton, Fiona Scott, Jorge Silva-Risso and Florian Zettelmeyer (2003), “Consmer Information and Price Discrimination: Does the Internet Affect the Pricing of New Cars to Women and Minorities?," Quantitative Marketing and Economics, 1(1), 65-92.

Purohit, Devavrat (1992), "Exploring the Relationship between the Markets for New and Used Durable Goods: The Case of Automobilies," Marketing Science, 11(2). 154-167.

Siddarth, S., Randolph E Bucklin, and Donald Morrison (1995), "Making the Cut: Modeling and Analyzing Choice Set Restriction in Scanner Panel Data," Journal of Marketing Research, 32 (August), 255-266.

Sullivan, Mary (1990), "Measuring Image Spillovers in Umbrella-branded Products," Journal of Business, 63(3), 309-329. 


\title{
A Study on Interactions of Competitive Promotions Between the New and Used Cars
}

\author{
Chang, Kwangpil*
}

\begin{abstract}
In a market where new and used cars are competing with each other, we would run the risk of obtaining biased estimates of cross elasticity between them if we focus on only new cars or on only used cars. Unfortunately, most of previous studies on the automobile industry have focused on only new car models without taking into account the effect of used cars' pricing policy on new cars' market shares and vice versa, resulting in inadequate prediction of reactive pricing in response to competitors' rebate or price discount. However, there are some exceptions. Purohit (1992) and Sullivan (1990) looked into both new and used car markets at the same time to examine the effect of new car model launching on the used car prices. But their studies have some limitations in that they employed the average used car prices reported in NADA Used Car Guide instead of actual transaction prices. Some of the conflicting results may be due to this problem in the data. Park (1998) recognized this problem and used the actual prices in his study. His work is notable in that he investigated the qualitative effect of new car model launching on the pricing policy of the used car in terms of reinforcement of brand equity. The current work also used the actual price like Park (1998) but the quantitative aspect of competitive price promotion between new and used cars of the same model was explored. In this study, I develop a model that assumes that the cross elasticity between new and used cars of the same model is higher than those amongst new cars and used cars of the different model. Specifically, I apply the nested logit model that assumes the car model choice at the first stage and the choice between new and used cars at the second stage. This proposed model is compared to the IIA (Independence of Irrelevant Alternatives) model that assumes that there is no decision hierarchy but that new and used cars of the different model are all substitutable at the first stage.

The data for this study are drawn from Power Information Network (PIN), an affiliate of J.D. Power and Associates. PIN collects sales transaction data from a sample of dealerships in the major metropolitan areas in the U.S. These are retail transactions, i.e., sales or leases to final consumers,
\end{abstract}

* Professor of Marketing, College of Business Administration, University of Seoul. 
excluding fleet sales and including both new car and used car sales. Each observation in the PIN database contains the transaction date, the manufacturer, model year, make, model, trim and other car information, the transaction price, consumer rebates, the interest rate, term, amount financed (when the vehicle is financed or leased), etc. I used data for the compact cars sold during the period January 2009 - June 2009. The new and used cars of the top nine selling models are included in the study: Mazda 3, Honda Civic, Chevrolet Cobalt, Toyota Corolla, Hyundai Elantra, Ford Focus, Volkswagen Jetta, Nissan Sentra, and Kia Spectra. These models in the study accounted for $87 \%$ of category unit sales. Empirical application of the nested logit model showed that the proposed model outperformed the IIA (Independence of Irrelevant Alternatives) model in both calibration and holdout samples. The other comparison model that assumes choice between new and used cars at the first stage and car model choice at the second stage turned out to be mis-specfied since the dissimilarity parameter (i.e., inclusive or categroy value parameter) was estimated to be greater than 1 .

Post hoc analysis based on estimated parameters was conducted employing the modified Lanczo's iterative method. This method is intuitively appealing. For example, suppose a new car offers a certain amount of rebate and gains market share at first. In response to this rebate, a used car of the same model keeps decreasing price until it regains the lost market share to maintain the status quo. The new car settle down to a lowered market share due to the used car's reaction. The method enables us to find the amount of price discount to main the status quo and equilibrium market shares of the new and used cars. In the first simulation, I used Jetta as a focal brand to see how its new and used cars set prices, rebates or APR interactively assuming that reactive cars respond to price promotion to maintain the status quo. The simulation results showed that the IIA model underestimates cross elasticities, resulting in suggesting less aggressive used car price discount in response to new cars' rebate than the proposed nested logit model. In the second simulation, I used Elantra to reconfirm the result for Jetta and came to the same conclusion. In the third simulation, I had Corolla offer $\$ 1,000$ rebate to see what could be the best response for Elantra's new and used cars. Interestingly, Elantra's used car could maintain the status quo by offering lower price discount $(\$ 160)$ than the new car (\$205).

In the future research, we might want to explore the plausibility of the alternative nested logit model. For example, the NUB model that assumes choice between new and used cars at the first stage and brand choice at the second stage could be a possibility even though it was rejected in the current study because of mis-specification (A dissimilarity parameter turned out to be higher than 1). The NUB model may have been rejected due to true mis-specification or data structure transmitted from a typical car dealership. In a typical car dealership, both new and used cars of the 
same model are displayed. Because of this fact, the BNU model that assumes brand choice at the first stage and choice between new and used cars at the second stage may have been favored in the current study since customers first choose a dealership (brand) then choose between new and used cars given this market environment. However, suppose there are dealerships that carry both new and used cars of various models, then the NUB model might fit the data as well as the BNU model. Which model is a better description of the data is an empirical question. In addition, it would be interesting to test a probabilistic mixture model of the BNU and NUB on a new data set.

Key words: Automobile industry, Nested logit model, Cross elasticity 